\title{
Sleep-Wake Disturbances in Parkinson's Disease: Current Evidence regarding Diagnostic and Therapeutic Decisions
}

\author{
Veralice Meireles Sales Bruin ${ }^{a} \quad$ Lia Rita Azeredo Bittencourt ${ }^{b}$ Sergio Tufik ${ }^{b}$ \\ ${ }^{a}$ Departamento de Medicina, Universidade Federal do Ceara, Fortaleza, e ${ }^{b}$ Departamento de Psicobiologia, \\ Universidade Federal de São Paulo, São Paulo, Brasil
}

\section{Key Words}

Parkinson's disease $\cdot$ Rapid eye movement sleep behavior disorder $\cdot$ Restless legs $\cdot$ Sleep apnea $\cdot$ Insomnia $\cdot$ Circadian disorder

\begin{abstract}
Sleep disorders have been frequently reported in patients with Parkinson's disease (PD). However, there is insufficient evidence to guide precise recommendations on some diagnostic and treatment strategies. Here, we review clinical studies dealing with sleep abnormalities in PD and present clinical recommendations. Previous studies describing insomnia, excessive daytime sleepiness, narcolepsy-like episodes, circadian changes, sleep-disordered breathing, rapid eye movement sleep behavior disorder, vivid dreams and restless legs syndrome are evaluated. Longitudinal studies associating sleep disorders with PD onset or clinical deterioration are rare: only one longitudinal study associated daytime sleepiness with PD onset. Evidence suggests that clinical investigations must include direct questioning about depressive symptoms, nocturnal cramps, pain, nocturia and nighttime off periods. A patient interview must be conducted regarding sleep symptoms, including nightmares, abnor-
\end{abstract}

mal behavior during sleep, snoring, restless legs syndrome and daytime sleepiness. Initial evidence indicates that light therapy improves motor function and depression. Advice on sleep hygiene, the treatment of concomitant depression and the careful use of dopaminergic drugs and hypnosedative agents should be considered. To date, very few controlled studies are available to make a recommendation for the management of sleep-wake disturbances in PD.

Copyright $\odot 2012$ S. Karger AG, Base

\section{Introduction}

Parkinson's disease (PD) is a progressive nervous system disease occurring most often after the age of 50 years and affecting all ethnic groups, with an estimated worldwide prevalence of $1.6-1.8 \%$ in persons over 65 years of age [1-4]. Although supporting evidence exists for genetic and environmental etiologies, the cause of PD is unknown $[5,6]$. Clinical pathological studies indicate that PD occurs secondarily to the degeneration of dopamineproducing cells in the substantia nigra. Nigrostriatal alpha-synucleinopathy plays a central role in the pathogenesis of PD, multiple system atrophy and dementia with

\section{KARGER \\ Fax +4161306 1234 \\ E-Mail karger@karger.ch}

www.karger.com
(C) 2012 S. Karger AG, Basel

0014-3022/12/0675-0257\$38.00/0

Accessible online at:

www.karger.com/ene
Dr. Veralice M.S. de Bruin

Departamento de Medicina, Universidade Federal do Ceará

Rua Prof. Costa Mendes 1608

Fortaleza, Ceará 60430-040 (Brazil)

Tel. +55 853242 1681, E-Mail veralice@ superig.com.br 
Lewy bodies. In spite of the fact that defective dopaminergic neurotransmission is central in $\mathrm{PD}$, many studies show that other neurotransmitter alterations also affect multiple brain areas $[7,8]$. The cardinal clinical features of PD include an asymmetric onset of bradykinesia, rigidity and resting tremor. Most idiopathic PD patients present with one or more of these motor features. At the beginning of the illness or as the disease progresses, postural instability and falls manifest, which adds to the disability and severity of the illness [9]. Despite advances in therapy, PD is still a progressive disorder frequently leading to motor disability and dementia. Given the recognized heterogeneous symptom presentation and progression of $\mathrm{PD}$, the complex therapeutic aspects of this illness need to be better understood.

Most PD patients progressively develop non-motor symptoms during the course of the disease. Depression, cognitive deterioration, dementia, postural hypotension and sleep abnormalities are some of the frequently reported non-motor symptoms [10]. It has recently been shown that in advanced stages of the disease, motor fluctuations, mood changes, drooling, tremors and sleep problems (described most commonly as middle- and latenight insomnia followed by daytime sleepiness) are the most troublesome symptoms from the patient's perspective [11]. Nocturia has also been reported as a disturbing symptom in PD. It is generally agreed that the disease worsens with the duration of illness [12] and old age. It has been demonstrated that non-motor symptoms can be disabling and significantly impair a patient's quality of life $[10,13,14]$. However, complications, both motor and non-motor, and responses to treatment differ widely between individuals [15]. It is possible that sleep alterations have a deleterious effect on motor performance and the clinical evolution of PD. More longitudinal studies on this subject may help to clarify this issue. Furthermore, understanding the interactions between motor and nonmotor symptoms can be useful as a guide to therapy.

Though often clinically neglected, sleep disorders are more frequently seen in PD patients than in the general population, with estimates ranging from 25 to $80 \%$ of patients [16-19]. The interactions between sleep and dopaminergic function and their implications for PD are far from understood. First, it has been demonstrated that sleep deprivation is related to increased dopaminergic sensitivity, and it is generally agreed that insomnia can precede manic episodes [20,21]. On the other hand, some PD patients have reduced symptoms in the morning, indicating a favorable effect of sleep on motor function [22, 23]. This apparent paradox remains unexplained, as does the question of why only a subgroup of patients benefit from sleep. These unsolved issues have been further challenged by a recent report confirming that sleep deprivation improves motor function in a subgroup of PD patients [24]. One possible explanation is that the influence of sleep or sleep deprivation on PD depends on some particular aspects of the disease in the patient. Sleep disorders such as insomnia, excessive daytime sleepiness, narcolepsy-like episodes, sleep-disordered breathing, circadian rhythm disorders, restless legs syndrome (RLS) and sleep-disordered rapid eye movement (REM) have all been reported in PD patients. To understand the magnitude of the problem, it is vital to note that insomnia and depressive symptoms are important and independent predictors of a poor quality of life due to health problems [25]. It has been shown that PD patients with sleep disorders are at an increased risk for mood disturbances, which can also affect the quality of life of spousal caregivers [26]. In spite of many studies on sleep disorders in PD, many questions remain. For instance, longitudinal studies can help to establish the cause-and-effect relationship between sleep abnormalities and clinical outcomes. Also, controlled studies evaluating therapies for sleep disorders in PD are scarce. Two important questions need to be answered: does PD predispose a patient to sleep disorders, and do sleep disorders influence the clinical evolution of PD?

A literature search of MEDLINE using the words 'sleep' and 'Parkinson's disease' found 1,530 studies extending back to 1956; with the inclusion of the term 'randomized', 63 studies were found, and among these, 16 were reviews. The evaluation of sleep in 44 studies was performed using the Parkinson's Disease Sleep Scale (PDSS), while 83 used the Epworth Sleepiness Scale (ESS), 31 the Pittsburgh Sleep Quality Index (PSQI) and 18 the Scales for Outcomes in PD (SCOPA)-sleep scale. Recently, a task force evaluating PD sleep scales recommended that (1) the PDSS and the PSQI should be used for screening, rating and measuring the severity of overall sleep problems; (2) the SCOPA-sleep scale should be used for rating overall sleep problems for the purposes of screening and measuring their severity; (3) the ESS should be used to screen for and measure severity of sleepiness; (4) the Inappropriate Sleep Composite Score (ISCS) should be used for screening and measuring daytime sleepiness or sleep attacks, and (5) the Stanford Sleepiness Scale (SSS) should be used for rating sleepiness and for measuring its severity at a specific moment [27]. This study also highlighted the lack of a need for new scales. It has been shown that problem-specific subitems of the PDSS are 
more accurate in predicting polysomnography-related changes when compared to the PDSS as a whole [28].

The aim of this article is to review our current knowledge about sleep and wake abnormalities in PD. We will discuss the most common sleep abnormalities, clinical phenomenology, neuropathological bases, clinical trials, longitudinal studies and the important questions for guiding future studies. We also aim to increase the awareness of sleep abnormalities in PD, discuss the complex evidence about the relationship between sleep and brain structure abnormalities and recommend directions for further research. In light of the fact that an evidencebased recommendation for the treatment of sleep-wake abnormalities in PD cannot be made presently, we review the available diagnostic and therapeutic options.

\section{Sleep Disorders}

\section{Insomnia}

Insomnia is defined as 'repeated difficulty with initiation, duration and/or maintenance of sleep, despite adequate opportunity with consequent daytime impairment such as fatigue, mood disturbances, social and occupational problems, daytime sleepiness, loss of energy, memory impairment, headaches and gastrointestinal complaints' [29]. Insomnia is the most common sleep complaint in PD [17, 30]. A variety of processes can be responsible for insomnia in $\mathrm{PD}$ patients such as the inability to move in bed, stiffness, nocturia, dystonic movements, cramps, medication effects, comorbid conditions such as depression and dementia, primary sleep disorders such as RLS and obstructive sleep apnea (OSA), and the neuropathological changes related to the disease itself [17, 31-35]. Therefore, it is necessary to conduct an investigative sleep anamnesis interview about nocturnal cramps, disturbing off periods, pain, depressive symptoms, sleeprelated breathing disorders, RLS and REM sleep behavior disorders. It has been reported that familial cases have the same level of non-motor symptoms as non-familial cases [36]; conversely, it has been shown that familial cases have more sleep disturbances [37].

Structural abnormalities of the brain have been suspected to play an important part in the genesis of sleep abnormalities in PD. Previously, connections have been made between sleep abnormalities and structural brain damage $[38,39]$. Recent studies using more advanced tools, such as functional MRI, SPECT and PET, have shed more light on the understanding of this complex subject [40-42]. However, at the present time, sleep fragmenta- tion and poor sleep quality have not been associated with specific brain abnormalities.

The effects of medication on sleep in PD are a much more controversial subject. Table 1 examines the effects of medications on sleep in PD. Generally, dopaminergic agents, particularly dopamine agonists, have been connected with somnolence and associated sleep attacks [43, 44]. Micallef et al. [45] showed that pramipexole induces sleepiness as assessed by the Multiple Sleep Latency Test (MSLT) in healthy young subjects, independent of disease-related sleep dysfunction. Other studies have indicated a beneficial effect of dopaminergic agents on sleep, probably as a consequence of improved functional ability [46-48]. Conversely, a large randomized trial has shown that both levodopa and sustained-release levodopa preparations are associated with insomnia [49]. In fact, the role of sustained-release preparations on sleep fragmentation has not been totally clarified. A 12-week open-label trial of $14 \mathrm{PD}$ patients using low doses of quetiapine showed a generally good tolerance and improvement of sleep quality and excessive daytime sleepiness [50]. Despite the great number of reports, controlled studies on the treatment of insomnia in PD are scarce. Consequently, an evidence-based recommendation cannot be made presently. Advice about sleep hygiene, the treatment of concomitant depression and the careful use of dopaminergic drugs and hypnosedative agents are all considered common-sense measures [51]. Insomnia increases with very high doses of dopaminergic agents; Watts et al. [52] reported that insomnia is equally worse after high doses of levodopa or ropinorole. Recently, several dopaminergic agents have been reported to improve sleep in PD (table 1) [50, 53-59]. A study involving 6 patients revealed that insomniac PD patients have an increased total sleep time after subthalamic nucleus stimulation [60]. A follow-up of 30 patients showed that bilateral high frequency subthalamic stimulation improved insomnia symptoms [61]. Insomnia has been reported as a side effect of rotigotine [62], selegiline [63], tolcapone [64] and reboxetine [65]. In summary, controlled trials involving a large number of patients that evaluate nocturnal performance and daytime consequences are required to reach any conclusions.

\section{Excessive Daytime Sleepiness}

Currently, many studies confirm that daytime sleepiness is a frequent and troublesome complaint in patients with PD [66-70]. The estimated prevalence of excessive daytime sleepiness in PD patients varies from 20 to $50 \%$ among studies, and this discrepancy may be related to 
Table 1. Research articles on therapies for sleep disorders in PD

\begin{tabular}{|c|c|c|c|c|c|}
\hline Authors & Year & $\begin{array}{l}\text { Patients } \\
\mathrm{n}\end{array}$ & Drug & Study design & Main findings \\
\hline Lees [46] & 1987 & 10 & L-Dopa HBS & Open-label study & $\begin{array}{l}\text { Improvement of nocturnal } \\
\text { bradykinesia, rigidity and tremor }\end{array}$ \\
\hline Leeman et al. [48] & 1987 & 11 & L-Dopa & $\begin{array}{l}\text { Randomized, double-blind, } \\
\text { placebo-controlled, } 4 \text { nights }\end{array}$ & $\begin{array}{l}\text { Improvement of morning motor } \\
\text { function }\end{array}$ \\
\hline Block et al. [49] & 1997 & 618 & $\begin{array}{l}\text { Sustained-release or } \\
\text { immediate-release L-Dopa }\end{array}$ & $\begin{array}{l}\text { De novo patients randomized - } \\
5 \text {-year follow-up }\end{array}$ & $\begin{array}{l}\text { Similar motor benefit; insomnia as a } \\
\text { side effect }\end{array}$ \\
\hline Reuter et al. [54] & 1999 & 6 & Apomorphine & Observational & $\begin{array}{l}\text { Reduction of nocturnal awakenings, } \\
\text { off periods, pain, dystonia and } \\
\text { nocturia }\end{array}$ \\
\hline Arnulf et al. [60] & 2000 & 5 & Deep nuclei stimulation & Observational & $\begin{array}{l}\text { VIM stimulation reduced tremor } \\
\text { without altering sleep or sleep } \\
\text { spindles; low frequency did not } \\
\text { induce sleep }\end{array}$ \\
\hline Lemke [65] & 2002 & 16 & Reboxetine & Open-label & Insomnia as side effect \\
\hline $\begin{array}{l}\text { Parkinson } \\
\text { Study Group [62] }\end{array}$ & 2003 & 242 & Rotigotine & $\begin{array}{l}\text { Randomized, double-blind, } \\
\text { placebo-controlled }\end{array}$ & Insomnia as side effect \\
\hline Romito et al. [61] & 2003 & 33 & $\begin{array}{l}\text { High-frequency stimulation } \\
\text { of the subthalamic nucleus }\end{array}$ & Observational & Improvement of insomnia \\
\hline Pacchetti et al. [44] & 2003 & 3 & Pramipexole, Ropinorole & Case description & $\begin{array}{l}\text { Increased daytime sleepiness } \\
\text { (polysomnography) }\end{array}$ \\
\hline Juri et al. [50] & 2005 & 14 & Quetiapine & Open-label, 12 weeks & $\begin{array}{l}\text { PSQI score improved; } \\
\text { ESS score was reduced }\end{array}$ \\
\hline Lyons et al. [63] & 2010 & 60 & Selegiline & 12-week open-label & Insomnia as side effect \\
\hline Trenkwalder et al. [57] & 2011 & 287 & Rotigotine & Double-blind, placebo-controlled & Improved sleep (PDSS) \\
\hline Ray Chaudhuri et al. [56] & 2012 & 189 & Ropinorole & 24-week, double-blind & Improved sleep quality (PDSS) \\
\hline
\end{tabular}

differences in age, disease duration and dopaminergic therapy [66, 70-73]. On the other hand, the reported prevalence of narcolepsy-like episodes and sleep attacks, a common terminology for sudden sleep episodes less frequently reported in PD, varies from 1 to $20 \%$. Most epidemiological studies have used the ESS, a subjective test, for the evaluation of daytime sleepiness [74]. Objective measures of sleepiness such as the MSLT and the Main- tenance Wakefulness Test are also used; however, these objective measures are not related to the ESS and probably reflect different parameters [75]. The relationship between subjective measures and objective measures of sleepiness have been found to be significant [67], weakly significant [76] and not significant [77]. Two MSLT-based studies showed pathological sleepiness in $19 \%$ of PD cases $[78,79]$. More information about the relationship be- 
tween subjective measures of sleepiness and the MSLT in PD is needed.

Generally, motor disability, presence of depression and dementia, concurrent medical/sleep illnesses and the impact of PD and medications on alertness all contribute to the manifestations of daytime sleepiness in PD. Yet, understanding the role of these symptoms is important for the evaluation of therapy for excessive daytime sleepiness [76]. At present, there is still a need to understand the etiopathogenic mechanisms of excessive daytime sleepiness in PD. Because disease duration and disease severity are predictors of excessive daytime sleepiness and sleep attacks, it has been suggested that specific brain histopathological alterations underlie sudden sleep episodes [71]. The degeneration of hypocretin neurons in PD patients has not been sufficiently studied. A reduction of hypocretin neurons as well as reduced cerebrospinal fluid hypocretin levels have been previously shown in PD patients [80]. Conversely, it has been demonstrated that there is no significant decrease of cerebrospinal fluid hypocretin in PD patients compared to controls [67, 81]. More studies on this issue are warranted. Recently, a reduction of the cerebellar peduncle, possibly indicating ventral tegmental area degeneration, has been associated with excessive daytime sleepiness in PD [41]. These results confirm that brain histopathological alterations underlie the pathogenesis of excessive daytime sleepiness and possible sudden sleep onset. It has also been suggested that all anti-Parkinson drugs can cause daytime sleepiness [82]. It is generally agreed that sleepiness correlates with disease severity and high doses of levodopa or dopaminergic agents $[73,76]$.

A review of daytime sleepiness in PD highlighted the importance of this symptom and its association with sudden sleep onset. A unique study showed that excessive daytime sleepiness might be associated with an increased risk of developing PD [83]. Narcolepsy-like episodes and sleep attacks occur more frequently in patients with daytime sleepiness and are related to disease severity $[71,84-$ 87]. Sleep attacks can manifest without warning and can be a potential cause of car accidents [88]. In contrast to these findings, one study showed that PD patients do not have more car accidents than controls [85].

Very few controlled studies on the effects of medication on sleepiness in PD have been published. The effect of modafinil on sleepiness in PD patients remains controversial. Studies have shown significant improvement [89], modest improvement [90] and no improvement of sleepiness [89]. Weintraub et al. [91] showed that atomoxetine significantly improved cognition and daytime sleepiness and was well tolerated. Nocturnally administered sodium oxybate has also been shown to improve daytime sleepiness and fatigue in PD [92]. It should be noted that fatigue has not been related to daytime sleepiness or nighttime sleep dysfunction and has been strongly influenced by the presence of depression and lower functional status [93].

\section{Circadian Rhythm Sleep Disorders}

Circadian rhythm sleep disorders potentially influence daytime and nocturnal dysfunctions. It is common to find that PD patients go to bed and wake up very early; therefore, a phase advance may occur [94]. Advanced sleep phase is usually associated with older age [95] and characterized by involuntary sleep and waking times that are generally more than $3 \mathrm{~h}$ earlier than usual sleep times. For patients with $\mathrm{PD}$, both age-related changes and brain damage can provoke circadian rhythm sleep abnormalities. This relationship deserves more careful clarification, although it is complex. For instance, a slower absorption rate of levodopa during nighttime, possibly related to delayed gastric emptying, has been reported in PD patients [96]. In agreement with this example, it has been documented that phase advance in PD is possibly influenced not only by age but also by dopaminergic therapy and disease severity $[97,98]$. Given the complexity of this issue, an abnormal pattern of daily activities [99] and associated comorbidities, such as depressive symptoms and daytime sleepiness, could also influence circadian rhythms [70,76]. Thus, the analysis of this complex issue must take all of these variables into careful consideration.

Recently, Cai et al. [100] showed that there are abnormalities in the molecular clock in PD. They studied 17 patients and showed a difference in the expression pattern of brain and muscle Arnt-like protein-1 (BMAL1) but not in the expression pattern of the period circadian protein homolog 1 (PER1) during the nighttime in PD patients. The relative abundance of BMAL1 was significantly lower in PD patients versus control subjects and, furthermore, the expression levels of BMAL1 correlated with the Unified Parkinson's Disease Rating Scale (UPDRS) score and with the PSQI [100]. These results show that there are abnormalities in the molecular clock in PD. The role of clock gene abnormality on sleepiness, sleep abnormalities and circadian changes in PD is of interest. In the same vein, an uncontrolled study of 12 patients showed that bright-light therapy at dusk improved motor function and sleep [101]. In a randomized, placebo-controlled study, $36 \mathrm{PD}$ patients received $30 \mathrm{~min}$ of 7,500-lux brightlight therapy over 15 days and showed a significant im- 
provement of tremor, UPDRS parts I, II and IV, and depression [102]. Currently, only these two studies have shown that light therapy at dusk and in the morning improves motor dysfunction, depression and agitation. Other studies on this subject are warranted. This preliminary evidence needs more clarification but offers new possible therapeutic perspectives, not only for sleep problems but also for motor and non-motor symptoms such as cognition and mood.

\section{REM Behavior Disorder}

Idiopathic REM behavior disorder (RBD) is characterized by a loss of normal atonia during REM sleep [103, 104]: simple or complex behavior, potentially violent, corresponding to enacted dreams [105]. Approximately 50\% of RBD individuals will develop PD, dementia with Lewy body or multiple system atrophy within 10 years, suggesting that the alpha-synuclein pathogenic process may start decades before the first symptoms [106]. RBD is predominant in elderly men. However, Ju et al. [107] recently showed that in younger individuals, RBD has a lower male-to-female ratio. Other gender differences have also been found. In elderly men, RBD is more often associated with neurodegenerative disorders; in women, the idiopathic form is more frequent. It has been suggested that in women, $\mathrm{RBD}$ is frequently associated with a high rate of antidepressant use and autoimmune disease [107].

Cognitive impairment has been observed in idiopathic $\mathrm{RBD}$ and in $\mathrm{RBD}$ associated with degenerative diseases [108]. A 2-year follow-up has shown a progressive deterioration of memory in $\mathrm{RBD}$, indicating 'an underlying evolving degenerative process' [109]. PD patients with clinically probable RBD are older, have a longer disease duration, more disability, a longer duration of anti-Parkinson medication and lower tremor scores in the UPDRS [110]. Interestingly, it has been shown that movements recorded in PD subjects with RBD during REM sleep have better speed (but less coordination) compared with the pattern of movements seen in the same subjects during wakefulness, suggesting that the movements during RBD are generated by the motor cortex and projected downstream via the pyramidal system bypassing the basal ganglia [111]. Postuma et al. [112] also showed that PD patients with RBD were less likely to be tremor predominant, had more falls and had lower amplitude response to their medication. The latter findings are indicative of a more severe form of PD. A unique and challenging study showed that patients with left-sided PD onset or predominant right hemisphere dysfunction have more nocturnal hallucinations and daytime dozing [113]. It has been sug- gested that visual hallucinations may be dream imagery coinciding with daytime episodes of REM sleep. Therefore, psychotic episodes could be narcolepsy-like REM sleep disorders [114]. A longitudinal evaluation has indicated that the presence of RBD in PD could be a warning sign for the development of cognitive impairment [115]. Most of the studies showing that PD patients with RBD have more cognitive impairment are cross-sectional, which makes a cause-and-effect relationship difficult to establish [108, 116, 117]. Previously, visual hallucinations have been described as a common symptom in PD patients with RBD [115]. Forsaa et al. [118] performed a 12year prospective evaluation of 130 patients and showed that psychotic symptoms in PD manifest at an older age of onset, require higher doses of dopaminergic drugs and occur in association with probable RBD. Interestingly, the same authors also showed that psychotic symptoms, age at onset, chronological age, motor severity and dementia independently predicted an increased mortality in $\mathrm{PD}$ patients [119]. Connections among psychotic symptoms, dementia and RBD have been previously established [120]. These results corroborate the evidence that $\mathrm{RBD}$ is a noxious manifestation of PD.

According to the International Classification of Sleep Disorders (ICSD) Minimal Criteria, a diagnosis of RBD can be made when limb or body movement is associated with dream-enacting behavior and at least one of the following occurs: (1) harmful or potentially harmful sleep behaviors; (2) dreams appear to be acted out, and/or (3) sleep behaviors disrupt sleep continuity. Polysomnographic abnormalities are additional criteria to confirm the diagnosis in dubious cases. In contrast, the 2 nd edition of the ICSD requires the following for the clinical diagnosis of RBD: (1) presence of REM sleep without atonia on polysomnography; (2) at least one of the following: (a) sleep-related, injurious, potentially injurious, or disruptive behaviors by history (i.e. dream-enacting behavior) and/or (b) abnormal REM sleep behavior documented during polysomnographic monitoring; (3) absence of EEG epileptiform activity during REM sleep unless RBD can be clearly distinguished from any concurrent REM sleep-related seizure disorder, and (4) the sleep disorder is not better explained by another sleep disorder, medical or neurological disorder, mental disorder, medication use or substance use disorder [121]. It has been shown that the majority of RBD patients report symptoms only in response to specific questioning; thus, investigative questioning during sleep anamnesis is necessary [122].

Clonazepam is efficacious in and well tolerated by the majority of patients afflicted by RBD and should be con- 
sidered as an initial treatment [123]. Careful surveillance of side effects, such as increased risk of falls, daytime sleepiness, confusional arousal, concomitant cognitive impairment or worsening of OSA, should be considered when using clonazepam. Melatonin or other benzodiazepines such as zopiclone and alprazolam may be good alternatives [124-126]. Monoamine oxidase inhibitors, tricyclic antidepressants, serotonergic synaptic reuptake inhibitors and noradrenergic antagonists can induce or aggravate RBD symptoms and should be avoided [123]. Results from a double-blind clinical-polysomnography study have shown that quetiapine improves visual hallucinations in PD [127].

\section{$R L S$}

RLS is a sensorimotor disorder. Its prevalence increases with age, and the incidence rates vary from 2 to $12 \%$ [128-130]. A preference for female gender [131] and a familial form with more precocious manifestations [132] have been described. RLS is characterized by an irresistible urge to move the legs and is usually accompanied by uncomfortable sensations. It manifests or worsens at rest, is exacerbated in the early evening or at night and is alleviated or partially alleviated by movement. End-stage renal disease [133, 134], iron deficiency [135], multiple sclerosis $[136,137]$ and the use of some drugs, such as antidepressants and antipsychotics [138], have been associated with RLS. Doubts remain about whether diabetic patients have a higher incidence of RLS [139, 140]. Despite high prevalence rates of RLS in PD, there is no evidence that RLS symptoms early in life predispose to the subsequent development of PD [141-143]. Patients with RLS frequently have periodic limb movements that can be diagnosed by polysomnography [144]. In similarity to RLS, periodic limb movements may involve dopamine mechanisms [145]. Few studies have addressed the issue of periodic limb movements in PD: it remains to be clarified whether periodic limb movements are more frequent in PD patients with RLS than in patients without.

Therapeutic options for RLS associated with PD are the same as in other clinical conditions and include palliative measures such as trying to maintain a regular sleep pattern, moderate exercise, massaging the legs, taking a hot bath or using a heating pad or ice pack. Dopaminergic agonists are the preferred drugs, and other medications such as levodopa [146], benzodiazepines, opioids, gabapentin and pregabalin can also be used [147].

\section{Sleep Disordered Breathing}

Previous studies indicate that OSA prevalence varies from 24 to $65 \%$ [148-151]. Contradictory evidence can be found showing both a higher prevalence of OSA in PD patients than in the general population $[67,149,151]$ and no increased risk of OSA in PD patients $[152,153]$. Studies suggest a relationship between daytime sleepiness and OSA in PD [67, 154]. Conversely, findings have also shown no relationship between daytime sleepiness and OSA in PD $[152,153]$. In fact, very few studies about sleep in PD involved polysomnography. Presently, there are no conclusive data regarding the prevalence of OSA in PD patients compared to the general population. Of greater importance is the need to clarify the possible deleterious effects of OSA in PD; studies on the effects of OSA therapy in $\mathrm{PD}$ are virtually non-existent.

\section{Conclusion}

Sleep abnormalities are common and significantly impair the quality of life of PD patients. Clinical investigations must include direct questioning about depressive symptoms, nocturnal cramps, pain and nighttime off periods. An interview about sleep symptoms, nightmares, abnormal behavior during sleep, RLS and daytime sleepiness must also be conducted. PD patients commonly have reduced daytime social activities and tend to go to bed early and wake up early. Preliminary evidence indicates that sleep hygiene measures and bright-light therapy could benefit sleep, cognitive performance and motor ability. It is important to diagnose and treat RBD in PD, and the majority of patients will benefit from the use of clonazepam. In cases with excessive daytime sleepiness, an emphasis on sleep hygiene and a warning about accidents are advised. Medications that promote alertness can be used, though this is not an evidence-based recommendation. The treatment of RLS with nighttime dopaminergic agonists is similar to other clinical situations. The results of continuous positive airway pressure therapy in PD are unknown. To date, very few controlled studies are available to make a recommendation for the management of insomnia in PD. Generally, for the treatment of sleep abnormalities in PD, the implementation of sleep hygiene, the treatment of concomitant depression and the careful use of dopaminergic drugs and hypnosedative agents should be considered. More prospective studies are necessary to clarify whether the onset of $\mathrm{PD}$ predisposes a patient to sleep abnormalities or if sleep abnormalities aggravate the course of illness. 


\section{Acknowledgement}

We wish to thank MCT/CNPq for supporting this study.

\section{Disclosure Statement}

V.M.S. de Bruin, L.R.A. Bittencourt and S. Tufik do not have a financial relationship with a commercial entity that has an interest in the subject of this study.

\section{References}

1 van de Vijver DA, Roos RA, Jansen PA, Porsius AJ, de Boer A: Estimation of incidence and prevalence of Parkinson's disease in the elderly using pharmacy records. Pharmacoepidemiol Drug Saf 2001;10:549-554.

-2 Muangpaisan W, Hori H, Brayne C: Systematic review of the prevalence and incidence of Parkinson's disease in Asia. J Epidemiol 2009; 19:281-293.

$\checkmark 3$ Trenkwalder C, Schwarz J, Gebhard J, et al: Starnberg trial on epidemiology of Parkinsonism and hypertension in the elderly. Prevalence of Parkinson's disease and related disorders assessed by a door-to-door survey of inhabitants older than 65 years. Arch Neurol 1995;52:1017-1022.

4 von Campenhausen S, Bornschein B, Wick $\mathrm{R}$, et al: Prevalence and incidence of Parkinson's disease in Europe. Eur Neuropsychopharmacol 2005; 15:473-490.

5 Schoenberg BS: Environmental risk factors for Parkinson's disease: the epidemiologic evidence. Can J Neurol Sci 1987;14:407-413.

$\checkmark 6$ Checkoway H, Nelson LM: Epidemiologic approaches to the study of Parkinson's disease etiology. Epidemiology 1999;10:327336.

$>7$ Rouse ST, Marino MJ, Bradley SR, Awad H, Wittmann M, Conn PJ: Distribution and roles of metabotropic glutamate receptors in the basal ganglia motor circuit: implications for treatment of Parkinson's disease and related disorders. Pharmacol Ther 2000;88: 427-435.

$>8$ Tan SK, Hartung H, Sharp T, Temel Y: Serotonin-dependent depression in Parkinson's disease: a role for the subthalamic nucleus? Neuropharmacology 2011;61:387-399.

$\checkmark 9$ Poewe W: The natural history of Parkinson's disease. J Neurol 2006;253(suppl 7):VII2VII6.

10 Martinez-Martin P, Rodriguez-Blazquez C, Kurtis MM, Chaudhuri KR: The impact of non-motor symptoms on health-related quality of life of patients with Parkinson's disease. Mov Disord 2011;26:399-406.

-11 Politis M, Wu K, Loane C, et al: Depressive symptoms in PD correlate with higher 5-HTT binding in raphe and limbic structures. Neurology 2010;75:1920-1927.

$>12$ Nausieda PA, Weiner WJ, Kaplan LR, Weber S, Klawans HL: Sleep disruption in the course of chronic levodopa therapy: an early feature of the levodopa psychosis. Clin Neuropharmacol 1982;5:183-194.
13 Margis R, Donis KC, Schonwald SV, Rieder CR: WHOQOL-OLD assessment of quality of life in elderly patients with Parkinson's disease: influence of sleep and depressive symptoms. Rev Bras Psiquiatr 2010;32:125131.

14 Gallagher DA, Lees AJ, Schrag A: What are the most important nonmotor symptoms in patients with Parkinson's disease and are we missing them? Mov Disord 2010;25:24932500.

15 Gunn DG, Naismith SL, Lewis SJ: Sleep disturbances in Parkinson disease and their potential role in heterogeneity. J Geriatr Psychiatry Neurol 2010;23:131-137.

-16 Zoccolella S, Savarese M, Lamberti P, Manni R, Pacchetti C, Logroscino G: Sleep disorders and the natural history of Parkinson's disease: the contribution of epidemiological studies. Sleep Med Rev 2011;15:41-50.

17 Menza M, Dobkin RD, Marin H, Bienfait K: Sleep disturbances in Parkinson's disease. Mov Disord 2010;25(suppl 1):S117-S122.

18 Matuja WB, Aris EA: Motor and non-motor features of Parkinson's disease. East Afr Med J 2008;85:3-9.

19 Barone P, Antonini A, Colosimo C, et al: The PRIAMO study: a multicenter assessment of nonmotor symptoms and their impact on quality of life in Parkinson's disease. Mov Disord 2009;24:1641-1649.

20 Wright JB: Mania following sleep deprivation. Br J Psychiatry 1993;163:679-680.

21 Gessa GL, Pani L, Fadda P, Fratta W: Sleep deprivation in the rat: an animal model of mania. Eur Neuropsychopharmacol 1995; 5(suppl):89-93.

-22 Currie LJ, Bennett JP Jr, Harrison MB, Trugman JM, Wooten GF: Clinical correlates of sleep benefit in Parkinson's disease. Neurology 1997;48:1115-1117.

23 Merello M, Hughes A, Colosimo C, Hoffman M, Starkstein S, Leiguarda R: Sleep benefit in Parkinson's disease. Mov Disord 1997;12: 506-508.

-24 Hogl B, Peralta C, Wetter TC, Gershanik O, Trenkwalder C: Effect of sleep deprivation on motor performance in patients with Parkinson's disease. Mov Disord 2001;16:616-621.

25 Forsaa EB, Larsen JP, Wentzel-Larsen T, Herlofson K, Alves G: Predictors and course of health-related quality of life in Parkinson's disease. Mov Disord 2008;23:1420-1427.
26 Pal PK, Thennarasu K, Fleming J, Schulzer M, Brown T, Calne SM: Nocturnal sleep disturbances and daytime dysfunction in patients with Parkinson's disease and in their caregivers. Parkinsonism Relat Disord 2004; 10:157-168.

-27 Hogl B, Arnulf I, Comella C, et al: Scales to assess sleep impairment in Parkinson's disease: critique and recommendations. Mov Disord 2010;25:2704-2716.

28 Norlinah MI, Afidah KN, Noradina AT, et al: Sleep disturbances in Malaysian patients with Parkinson's disease using polysomnography and PDSS. Parkinsonism Relat Disord 2009;15:670-674.

29 Buysse DJ, Reynolds CF, 3rd, Kupfer DJ, et al: Clinical diagnoses in 216 insomnia patients using the International Classification of Sleep Disorders (ICSD), DSM-IV and ICD10 categories: a report from the APA/NIMH DSM-IV Field Trial. Sleep 1994;17:630-637.

30 McDonald WM, Richard IH, DeLong MR: Prevalence, etiology, and treatment of depression in Parkinson's disease. Biol Psychiatry 2003;54:363-375.

31 Naismith SL, Hickie IB, Lewis SJ: The role of mild depression in sleep disturbance and quality of life in Parkinson's disease. J Neuropsychiatry Clin Neurosci 2010;22:384389.

32 Gomez-Esteban JC, Tijero B, Somme J, et al: Impact of psychiatric symptoms and sleep disorders on the quality of life of patients with Parkinson's disease. J Neurol 2011;258: 494-499.

33 Gjerstad MD, Wentzel-Larsen T, Aarsland D, Larsen JP: Insomnia in Parkinson's disease: frequency and progression over time. J Neurol Neurosurg Psychiatry 2007;78:476479 .

34 Suzuki K, Okuma Y, Hattori N, et al: Characteristics of sleep disturbances in Japanese patients with Parkinson's disease. A study using Parkinson's disease sleep scale. Mov Disord 2007;22:1245-1251.

35 Bugalho P, da Silva JA, Neto B: Clinical features associated with REM sleep behavior disorder symptoms in the early stages of Parkinson's disease. J Neurol 2011;258:50-55.

36 Prueksaritanond S, Boongird P, Pulkes T: Clinical features of familial Parkinson's disease in Thai patients. Qual Prim Care 2009; 17:115-122. 
- 37 Vibha D, Shukla G, Singh S, Goyal V, Srivastava $\mathrm{AK}$, Behari M: Lower prevalence of sleep disturbances in familial versus sporadic Parkinson's disease: a questionnaire based study. J Neurol Sci 2010;295:27-30.

- 38 Bliwise DL, Watts RL, Watts N, Rye DB, Irbe D, Hughes M: Disruptive nocturnal behavior in Parkinson's disease and Alzheimer's disease. J Geriatr Psychiatry Neurol 1995;8:107110.

-39 Schäfer D, Greulich W: Effects of parkinsonian medication on sleep. J Neurol 2000; 247(suppl 4):IV/24-IV/27.

-40 Unger MM, Belke M, Menzler K, et al: Diffusion tensor imaging in idiopathic rem sleep behavior disorder reveals microstructural changes in the brainstem, substantia nigra, olfactory region, and other brain regions. Sleep 2010;33:767-773.

-41 Gama RL, Tavora DG, Bomfim RC, Silva CE, de Bruin VM, de Bruin PF: Sleep disturbances and brain MRI morphometry in Parkinson's disease, multiple system atrophy and progressive supranuclear palsy - a comparative study. Parkinsonism Relat Disord 2010; 16:275-279.

42 Iranzo A, Lomeña F, Stockner H, et al: Decreased striatal dopamine transporter uptake and substantia nigra hyperechogenicity as risk markers of synucleinopathy in patients with idiopathic rapid-eye-movement sleep behaviour disorder: a prospective study. Lancet Neurol 2010;9:1070-1077.

-43 Clarenbach P, Greulich W, Meinck HM, et al: Workshop I: Parkinson's disease and sleep results of the group discussion. J Neurol 2000;247(suppl 4):IV/34-IV/35.

-44 Pacchetti C, Martignoni E, Terzaghi M, et al: Sleep attacks in Parkinson's disease: a clinical and polysomnographic study. Neurol Sci 2003;24:195-196.

-45 Micallef J, Rey M, Eusebio A, et al: Antiparkinsonian drug-induced sleepiness: a double-blind placebo-controlled study of L-do$\mathrm{pa}$, bromocriptine and pramipexole in healthy subjects. Br J Clin Pharmacol 2009; 67:333-340

-46 Lees AJ: A sustained-release formulation of L-dopa (Madopar HBS) in the treatment of nocturnal and early-morning disabilities in Parkinson's disease. Eur Neurol 1987;27 (suppl 1):126-134.

-47 Askenasy JJ, Yahr MD: Reversal of sleep disturbance in Parkinson's disease by antiparkinsonian therapy: a preliminary study. Neurology 1985;35:527-532.

-48 Leeman AL, O’Neill CJ, Nicholson PW, et al: Parkinson's disease in the elderly: response to and optimal spacing of night time dosing with levodopa. Br J Clin Pharmacol 1987;24: 637-643.

49 Block G, Liss C, Reines S, Irr J, Nibbelink D: Comparison of immediate-release and controlled release carbidopa/levodopa in Parkinson's disease. A multicenter 5-year study. The CR First Study Group. Eur Neurol 1997; $37: 23-27$.
50 Juri C, Chana P, Tapia J, Kunstmann C Parrao T: Quetiapine for insomnia in Parkinson disease: results from an open-label trial. Clin Neuropharmacol 2005;28:185187.

51 Larsen JP, Tandberg E: Sleep disorders in patients with Parkinson's disease: epidemiology and management. CNS Drugs 2001;15: 267-275.

-52 Watts RL, Lyons KE, Pahwa R, et al: Onset of dyskinesia with adjunct ropinirole prolonged-release or additional levodopa in early Parkinson's disease. Mov Disord 2010;25: 858-866.

53 Menza M, Dobkin RD, Marin H, et al: Treatment of insomnia in Parkinson's disease: A controlled trial of eszopiclone and placebo. Mov Disord 2010;25:1708-1714.

54 Reuter I, Ellis CM, Ray Chaudhuri K: Nocturnal subcutaneous apomorphine infusion in Parkinson's disease and restless legs syndrome. Acta Neurol Scand 1999;100:163167.

55 Nodel MR: Effects of the dopamine agonist mirapex (pramipexole) therapy on sleep disorders in Parkinson's disease (in Russian). Zh Nevrol Psikhiatr Im S S Korsakova 2010; 110:42-47.

56 Ray Chaudhuri K, Martinez-Martin P, Rolfe $\mathrm{KA}$, et al: Improvements in nocturnal symptoms with ropinirole prolonged release in $\mathrm{pa}$ tients with advanced Parkinson's disease. Eur J Neurol 2012;19:105-113.

57 Trenkwalder C, Kies B, Rudzinska M, et al: Rotigotine effects on early morning motor function and sleep in Parkinson's disease: A double-blind, randomized, placebo-controlled study (RECOVER). Mov Disord 2011; 26:90-99.

58 Menza M, Dobkin RD, Marin H, et al: A controlled trial of antidepressants in patients with Parkinson disease and depression. Neurology 2009;72:886-892.

59 Waters CH, Kurth M, Bailey P, et al: Tolcapone in stable Parkinson's disease: efficacy and safety of long-term treatment. Tolcapone Stable Study Group. Neurology 1998; 50:S39-S45.

60 Arnulf I, Bejjani BP, Garma L, et al: Effect of low and high frequency thalamic stimulation on sleep in patients with Parkinson's disease and essential tremor. J Sleep Res 2000;9:55-62.

61 Romito LM, Scerrati M, Contarino MF, Iacoangeli M, Bentivoglio AR, Albanese A: Bilateral high frequency subthalamic stimulation in Parkinson's disease: long-term neurological follow-up. J Neurosurg Sci 2003;47: 119-128.

62 Parkinson Study Group: A controlled trial of rotigotine monotherapy in early Parkinson's disease. Arch Neurol 2003;60:1721-1728.

63 Lyons KE, Friedman JH, Hermanowicz N, et al: Orally disintegrating selegiline in Parkinson patients with dopamine agonist-related adverse effects. Clin Neuropharmacol 2010; 33:5-10.
64 Truong DD: Tolcapone: review of its pharmacology and use as adjunctive therapy in patients with Parkinson's disease. Clin Interv Aging 2009;4:109-113.

65 Lemke MR: Effect of reboxetine on depression in Parkinson's disease patients. J Clin Psychiatry 2002;63:300-304.

-66 Suzuki K, Miyamoto T, Miyamoto M, et al: Excessive daytime sleepiness and sleep episodes in Japanese patients with Parkinson's disease. J Neurol Sci 2008;271:47-52.

-67 Poryazova R, Benninger D, Waldvogel D, Bassetti CL: Excessive daytime sleepiness in Parkinson's disease: characteristics and determinants. Eur Neurol 2010;63:129-135.

68 Ondo WG, Dat Vuong K, Khan H, Atassi F, Kwak C, Jankovic J: Daytime sleepiness and other sleep disorders in Parkinson's disease. Neurology 2001;57:1392-1396.

69 O’Suilleabhain PE, Dewey RB Jr: Contributions of dopaminergic drugs and disease severity to daytime sleepiness in Parkinson disease. Arch Neurol 2002;59:986-989.

70 Braga-Neto P, da Silva-Junior FP, Sueli Monte F, de Bruin PF, de Bruin VM: Snoring and excessive daytime sleepiness in Parkinson's disease. J Neurol Sci 2004;217:41-45.

-71 Korner Y, Meindorfner C, Moller JC, et al: Predictors of sudden onset of sleep in Parkinson's disease. Mov Disord 2004;19:1298-1305.

72 Gjerstad MD, Alves G, Wentzel-Larsen T, Aarsland D, Larsen JP: Excessive daytime sleepiness in Parkinson disease: is it the drugs or the disease? Neurology 2006;67: 853-858.

73 Verbaan D, van Rooden SM, Visser M, Marinus J, van Hilten JJ: Nighttime sleep problems and daytime sleepiness in Parkinson's disease. Mov Disord 2008;23:35-41.

74 Johns MW: A new method for measuring daytime sleepiness: the Epworth sleepiness scale. Sleep 1991;14:540-545.

75 Buysse DJ, Hall ML, Strollo PJ, et al: Relationships between the Pittsburgh Sleep Quality Index (PSQI), Epworth Sleepiness Scale (ESS), and clinical/polysomnographic measures in a community sample. J Clin Sleep Med 2008;4:563-571.

76 Arnulf I: Excessive daytime sleepiness in parkinsonism. Sleep Med Rev 2005;9:185-200.

$\checkmark 77$ Kaynak D, Kiziltan G, Kaynak H, Benbir G Uysal O: Sleep and sleepiness in patients with Parkinson's disease before and after dopaminergic treatment. Eur J Neurol 2005; 12 : 199-207.

78 Rye DB, Bliwise DL, Dihenia B, Gurecki P: Fast track: daytime sleepiness in Parkinson's disease. J Sleep Res 2000;9:63-69.

79 Razmy A, Lang AE, Shapiro CM: Predictors of impaired daytime sleep and wakefulness in patients with Parkinson disease treated with older (ergot) vs newer (nonergot) dopamine agonists. Arch Neurol 2004;61:97-102.

80 Fronczek R, Overeem S, Lee SY, et al: Hypocretin (orexin) loss and sleep disturbances in Parkinson's disease. Brain 2008;131:e88. 
-81 Compta Y, Santamaria J, Ratti L, et al: Cerebrospinal hypocretin, daytime sleepiness and sleep architecture in Parkinson's disease dementia. Brain 2009;132:3308-3317.

-82 Sanjiv CC, Schulzer M, Mak E, et al: Daytime somnolence in patients with Parkinson's disease. Parkinsonism Relat Disord 2001;7:283286.

83 Abbott RD, Ross GW, White LR, et al: Excessive daytime sleepiness and subsequent development of Parkinson disease. Neurology 2005;65:1442-1446.

84 Arnulf I, Konofal E, Merino-Andreu M, et al: Parkinson's disease and sleepiness: an integral part of PD. Neurology 2002;58:1019-1024.

-85 Montastruc JL, Brefel-Courbon C, Senard $J M$, et al: Sleep attacks and antiparkinsonian drugs: a pilot prospective pharmacoepidemiologic study. Clin Neuropharmacol 2001; 24:181-183.

86 Hobson DE, Lang AE, Martin WR, Razmy A, Rivest J, Fleming J: Excessive daytime sleepiness and sudden-onset sleep in Parkinson disease: a survey by the Canadian Movement Disorders Group. JAMA 2002;287: 455-463.

87 Ghorayeb I, Loundou A, Auquier P, Dauvilliers Y, Bioulac B, Tison F: A nationwide survey of excessive daytime sleepiness in Parkinson's disease in France. Mov Disord 2007; 22:1567-1572.

88 Meindorfner C, Korner Y, Moller JC, Stiasny-Kolster K, Oertel WH, Kruger HP: Driving in Parkinson's disease: mobility, accidents, and sudden onset of sleep at the wheel. Mov Disord 2005;20:832-842.

89 Hogl B, Saletu M, Brandauer E, et al: Modafinil for the treatment of daytime sleepiness in Parkinson's disease: a doubleblind, randomized, crossover, placebo-controlled polygraphic trial. Sleep 2002;25: 905-909.

90 Adler CH, Caviness JN, Hentz JG, Lind M, Tiede J: Randomized trial of modafinil for treating subjective daytime sleepiness in patients with Parkinson's disease. Mov Disord 2003; 18:287-293.

-91 Weintraub D, Mavandadi S, Mamikonyan E, et al: Atomoxetine for depression and other neuropsychiatric symptoms in Parkinson disease. Neurology 2010;75:448455.

92 Ondo WG, Perkins T, Swick T, et al: Sodium oxybate for excessive daytime sleepiness in Parkinson disease: an open-label polysomnographic study. Arch Neurol 2008;65: 1337-1340.

93 Havlikova E, van Dijk JP, Rosenberger J, et al: Fatigue in Parkinson's disease is not related to excessive sleepiness or quality of sleep. J Neurol Sci 2008;270:107-113.

$\$ 94$ Bordet R, Devos D, Brique S, et al: Study of circadian melatonin secretion pattern at different stages of Parkinson's disease. Clin Neuropharmacol 2003;26:65-72.
95 Carrier J, Monk TH, Buysse DJ, Kupfer DJ: Inducing a 6-hour phase advance in the elderly: effects on sleep and temperature rhythms. J Sleep Res 1996;5:99-105.

-96 Nyholm D, Lennernas H, Johansson A, Estrada M, Aquilonius SM: Circadian rhythmicity in levodopa pharmacokinetics in patients with Parkinson disease. Clin Neuropharmacol 2010;33:181-185.

-97 Fertl E: Comment to the paper of Medeiros CAM, et al. (2007) J Neurol 254:459-464. J Neurol 2008;255:758; author reply 759.

$\$ 98$ Santiago PL, Rossi M, Cardinali DP, Merello M: Activity-rest rhythm abnormalities in Parkinson's disease patients are related to dopaminergic therapy. Int J Neurosci 2010;120:11-16.

$\$ 99$ Camara Magalhaes S, Vitorino Souza C, Rocha Dias T, Felipe Carvalhedo de Bruin P, de Bruin VM: Lifestyle regularity measured by the social rhythm metric in Parkinson's disease. Chronobiol Int 2005;22: 917-924.

100 Cai Y, Liu S, Sothern RB, Xu S, Chan P: Expression of clock genes Perl and Bmall in total leukocytes in health and Parkinson's disease. Eur J Neurol 2010;17:550-554.

101 Willis GL, Turner EJ: Primary and secondary features of Parkinson's disease improve with strategic exposure to bright light: a case series study. Chronobiol Int 2007;24: 521-537.

102 Paus S, Schmitz-Hubsch T, Wullner U, Vogel A, Klockgether T, Abele M: Bright light therapy in Parkinson's disease: a pilot study. Mov Disord 2007;22:1495-1498.

103 Postuma RB, Gagnon JF, Rompre S, Montplaisir JY: Severity of REM atonia loss in idiopathic REM sleep behavior disorder predicts Parkinson disease. Neurology 2010; 74:239-244.

104 Montplaisir J, Gagnon JF, Fantini ML, et al: Polysomnographic diagnosis of idiopathic REM sleep behavior disorder. Mov Disord 2010;25:2044-2051.

105 Cygan F, Oudiette D, Leclair-Visonneau L, Leu-Semenescu S, Arnulf I: Night-to-night variability of muscle tone, movements, and vocalizations in patients with REM sleep behavior disorder. J Clin Sleep Med 2010;6: 551-555.

106 Claassen DO, Josephs KA, Ahlskog JE, Silber MH, Tippmann-Peikert M, Boeve BF: REM sleep behavior disorder preceding other aspects of synucleinopathies by up to half a century. Neurology 2010;75:494-499.

107 Ju YE, Larson-Prior L, Duntley S: Changing demographics in REM sleep behavior disorder: possible effect of autoimmunity and antidepressants. Sleep Med 2011;12:278283.

108 Gagnon JF, Vendette M, Postuma RB, et al: Mild cognitive impairment in rapid eye movement sleep behavior disorder and Parkinson's disease. Ann Neurol 2009;66:3947.
09 Fantini ML, Farini E, Ortelli P, et al: Longitudinal study of cognitive function in idiopathic REM sleep behavior disorder. Sleep 2011;34:619-625.

110 Lee JE, Kim KS, Shin HW, Sohn YH: Factors related to clinically probable REM sleep behavior disorder in Parkinson disease. Parkinsonism Relat Disord 2010;16: 105-108.

111 De Cock VC, Vidailhet M, Leu S, et al: Restoration of normal motor control in Parkinson's disease during REM sleep. Brain 2007; 130:450-456.

112 Postuma RB, Gagnon JF, Vendette M, Charland K, Montplaisir J: REM sleep behaviour disorder in Parkinson's disease is associated with specific motor features. J Neurol Neurosurg Psychiatry 2008;79: 1117-1121.

113 Stavitsky K, McNamara P, Durso R, Harris E, Auerbach S, Cronin-Golomb A: Hallucinations, dreaming, and frequent dozing in Parkinson disease: impact of right-hemisphere neural networks. Cogn Behav Neurol 2008;21:143-149.

114 Arnulf I, Bonnet AM, Damier P, et al: Hallucinations, REM sleep, and Parkinson's disease: a medical hypothesis. Neurology 2000;55:281-288.

115 Sinforiani E, Pacchetti C, Zangaglia R, Pasotti C, Manni R, Nappi G: REM behavior disorder, hallucinations and cognitive impairment in Parkinson's disease: a two-year follow up. Mov Disord 2008;23:1441-1445.

116 Marion MH, Qurashi M, Marshall G, Foster O: Is REM sleep behaviour disorder (RBD) a risk factor of dementia in idiopathic Parkinson's disease? J Neurol 2008;255: 192-196.

117 Terzaghi M, Sinforiani E, Zucchella C, et al: Cognitive performance in REM sleep behaviour disorder: a possible early marker of neurodegenerative disease? Sleep Med 2008;9:343-351.

118 Forsaa EB, Larsen JP, Wentzel-Larsen T, et al: A 12-year population-based study of psychosis in Parkinson disease. Arch Neurol 2010;67:996-1001.

119 Forsaa EB, Larsen JP, Wentzel-Larsen T, Alves G: What predicts mortality in Parkinson disease? A prospective populationbased long-term study. Neurology 2010;75: $1270-1276$

120 Pacchetti C, Manni R, Zangaglia R, et al: Relationship between hallucinations, delusions, and rapid eye movement sleep behavior disorder in Parkinson's disease. Mov Disord 2005;20:1439-1448.

121 International Classification of Sleep Disorders: Diagnostic and Coding Manual, ed 2. American Academy of Sleep Medicine. Westchester, 2005.

122 Frauscher B, Gschliesser V, Brandauer E, et al: REM sleep behavior disorder in 703 sleep-disorder patients: the importance of eliciting a comprehensive sleep history. Sleep Med 2010;11:167-171. 
123 Gagnon JF, Postuma RB, Montplaisir J: Update on the pharmacology of REM sleep behavior disorder. Neurology 2006;67:742747.

124 Boeve BF, Silber MH, Ferman TJ: Melatonin for treatment of REM sleep behavior disorder in neurologic disorders: results in 14 patients. Sleep Med 2003;4:281-284.

-125 Sforza E, Krieger J, Petiau C: REM sleep behavior disorder: clinical and physiopathological findings. Sleep Med Rev 1997;1:5769.

126 Anderson KN, Shneerson JM: Drug treatment of REM sleep behavior disorder: the use of drug therapies other than clonazepam. J Clin Sleep Med 2009;5:235-239.

127 Fernandez HH, Okun MS, Rodriguez RL, et al: Quetiapine improves visual hallucinations in Parkinson disease but not through normalization of sleep architecture: results from a double-blind clinical-polysomnography study. Int J Neurosci 2009;119:21962205.

-128 Yilmaz K, Kilincaslan A, Aydin N, Kor D: Prevalence and correlates of restless legs syndrome in adolescents. Dev Med Child Neurol 2011;53:40-47.

129 Allen RP, Walters AS, Montplaisir J, et al: Restless legs syndrome prevalence and impact: REST general population study. Arch Intern Med 2005;165:1286-1292.

130 Nomura T, Inoue Y, Miyake M, Yasui K, Nakashima K: Prevalence and clinical characteristics of restless legs syndrome in Japanese patients with Parkinson's disease. Mov Disord 2006;21:380-384.

-131 Juuti AK, Laara E, Rajala U, et al: Prevalence and associated factors of restless legs in a 57-year-old urban population in northern Finland. Acta Neurol Scand 2010;122: 63-69.

132 Hanson M, Honour M, Singleton A, Crawley A, Hardy J, Gwinn-Hardy K: Analysis of familial and sporadic restless legs syndrome in age of onset, gender, and severity features. J Neurol 2004;251:1398-1401.
133 Araujo SM, de Bruin VM, Nepomuceno LA, et al: Restless legs syndrome in endstage renal disease: clinical characteristics and associated comorbidities. Sleep Med 2010;11:785-790.

134 Bastos JP, Sousa RB, Nepomuceno LA, et al: Sleep disturbances in patients on maintenance hemodialysis: role of dialysis shift. Rev Assoc Med Bras 2007;53:492-496.

135 Zucconi M, Ferini-Strambi L: Epidemiology and clinical findings of restless legs syndrome. Sleep Med 2004;5:293-299.

136 Moreira NC, Damasceno RS, Medeiros CA, et al: Restless leg syndrome, sleep quality and fatigue in multiple sclerosis patients. Braz J Med Biol Res 2008;41:932-937.

137 Manconi M, Ferini-Strambi L, Filippi M, et al: Multicenter case-control study on restless legs syndrome in multiple sclerosis: The REMS study. Sleep 2008;31:944-952.

138 Chou KJ, Chen PY, Huang MC: Restless legs syndrome following the combined use of quetiapine and paroxetine. Prog Neuropsychopharmacol Biol Psychiatry 2010;34: 1139-1140.

139 Lopes LA, Lins Cde M, Adeodato VG, et al: Restless legs syndrome and quality of sleep in type 2 diabetes. Diabetes Care 2005;28: 2633-2636.

140 Merlino G, Valente M, Serafini A, et al: Effects of restless legs syndrome on quality of life and psychological status in patients with type 2 diabetes. Diabetes Educ 2010; 36:79-87.

141 Ondo WG, Vuong KD, Jankovic J: Exploring the relationship between Parkinson disease and restless legs syndrome. Arch Neurol 2002;59:421-424.

142 Garcia-Borreguero D, Odin P, Serrano C: Restless legs syndrome and PD: a review of the evidence for a possible association. Neurology 2003;61:S49-S55.

143 Rye DB: Parkinson's disease and RLS: the dopaminergic bridge. Sleep Med 2004;5: 317-328.

144 Iranzo A, Comella CL, Santamaria J, Oertel W: Restless legs syndrome in Parkinson's disease and other neurodegenerative diseases of the central nervous system. Mov Disord 2007;22(suppl 18):S424-S430.
45 Happe S, Pirker W, Klosch G, Sauter C, Zeitlhofer J: Periodic leg movements in patients with Parkinson's disease are associated with reduced striatal dopamine transporter binding. J Neurol 2003;250:83-86.

146 Scholz H, Trenkwalder C, Kohnen R, Riemann D, Kriston L, Hornyak M: Levodopa for restless legs syndrome. Cochrane Database Syst Rev 2011;2:CD005504.

147 Chesson AL Jr, Wise M, Davila D, et al: Practice parameters for the treatment of restless legs syndrome and periodic limb movement disorder. An American Academy of Sleep Medicine Report. Standards of Practice Committee of the American Academy of Sleep Medicine. Sleep 1999;22:961968.

148 Happe S, Schrodl B, Faltl M, Muller C, Auff E, Zeitlhofer J: Sleep disorders and depression in patients with Parkinson's disease. Acta Neurol Scand 2001;104:275-280.

149 Noradina AT, Karim NA, Hamidon BB, Norlinah I, Raymond AA: Sleep-disordered breathing in patients with Parkinson's disease. Singapore Med J 2010;51:6064.

150 Medeiros CA, Carvalhedo de Bruin PF, Lopes LA, Magalhaes MC, de Lourdes Seabra M, de Bruin VM: Effect of exogenous melatonin on sleep and motor dysfunction in Parkinson's disease. A randomized, double blind, placebo-controlled study. J Neurol 2007;254:459-464.

151 Diederich NJ, Vaillant M, Leischen M, et al Sleep apnea syndrome in Parkinson's disease. A case-control study in 49 patients. Mov Disord 2005;20:1413-1418.

152 Trotti LM, Bliwise DL: No increased risk of obstructive sleep apnea in Parkinson's disease. Mov Disord 2010;25:2246-2249.

153 Cochen De Cock V, Abouda M, Leu S, et al: Is obstructive sleep apnea a problem in Parkinson's disease? Sleep Med 2010;11:247252.

154 Monaca C, Ozsancak C, Jacquesson JM, et al: Effects of bilateral subthalamic stimulation on sleep in Parkinson's disease. J Neurol 2004;251:214-218. 